Published in final edited form as:

Arab J Gastroenterol. 2019 June ; 20(2): 107-108. doi:10.1016/j.ajg.2018.12.003.

\title{
Colocolic Intussusception
}

\author{
Nadim Mahmud, MD MS MPH ${ }^{1}$ and Kirk Wangensteen, MD PhD ${ }^{1}$ \\ ${ }^{1}$ Division of Gastroenterology, Hospital of the University of Pennsylvania, Philadelphia PA
}

\begin{abstract}
A 76-year-old male with a history of dementia presented to our emergency department with a five-day history of progressively worsening hematochezia. Physical examination was notable for a distended but soft abdomen which was tympanic to percussion. Laboratory studies revealed a mild leukocytosis. On computed tomography (CT) of his abdomen there was concern for colocolic intussusception with high-grade obstruction (Figure 1a/b, arrow). Sigmoidoscopy was pursued to attempt endoscopic decompression and identify the anticipated lead point, which was found to be a friable mass (Figure 2, arrow). The intussusceptum was partially reduced and the patient subsequently underwent exploratory laparotomy that revealed an obvious intussusception originating at the splenic flexure. Partial colectomy $(29 \mathrm{~cm})$ with end colostomy was performed. Pathology demonstrated a $7 \mathrm{~cm}$ tubulovillous adenoma with focal high-grade dysplasia, with surrounding mucosal necrosis, hemorrhage, and submucosal edema. The patient's initial post-operative course was complicated by respiratory failure resulting in tracheostomy, and small bowel obstruction requiring small bowel resection. He subsequently improved and was discharged to a rehabilitation facility.
\end{abstract}

Although intussusception is common among children, it is rare among adults, accounting for only $1-5 \%$ of all bowel obstructions [1]. Additionally, whereas intussusception is usually primary and benign in children, adult intussusception is associated with a definable lesion (lead point) in nearly $90 \%$ of cases. Colocolic intussusception is more commonly associated with malignant lead points ( $65 \%)$ than small bowel intussusception [2]. As such-although management surrounding endoscopic reduction is controversial-surgical en bloc resection of symptomatic colocolic lesions is the preferred management due to the theoretical risk of malignant seeding [3]. If there is diagnostic uncertainty, or unclear presence of a lead point based on imaging, sigmoidoscopy or colonoscopy has been used as a diagnostic tool, typically prior to definitive surgical management.

\section{Acknowledgments}

Funding: Nadim Mahmud is supported by a National Institutes of Health T32 grant (2-T32-DK007740-21A1).

Corresponding Author: Nadim Mahmud, MD MS MPH, University of Pennsylvania, 3400 Civic Center Boulevard, Philadelphia, PA 19104,nadim.mahmud@uphs.upenn.edu, Phone: 1-215-349-8222, Fax: 1-215-349-5914.

Disclosures/Conflict of Interests: The authors declare that they do not have any conflicts of interest that are relevant to this work.

Publisher's Disclaimer: This is a PDF file of an unedited manuscript that has been accepted for publication. As a service to our customers we are providing this early version of the manuscript. The manuscript will undergo copyediting, typesetting, and review of the resulting proof before it is published in its final citable form. Please note that during the production process errors may be discovered which could affect the content, and all legal disclaimers that apply to the journal pertain. 


\section{References}

1. Wilson Abralena, Elias George, and Dupiton Rulx. "Adult colocolic intussusception and literature review." Case reports in gastroenterology 73 (2013): 381-387. [PubMed: 24163649]

2. Marinis Athanasios, et al. "Intussusception of the bowel in adults: a review." World journal of gastroenterology: WJG 154 (2009): 407. [PubMed: 19152443]

3. Hanan B, et al. "Intussusception in adults: a retrospective study." Colorectal Disease 126 (2010): 574-578. [PubMed: 19486100] 


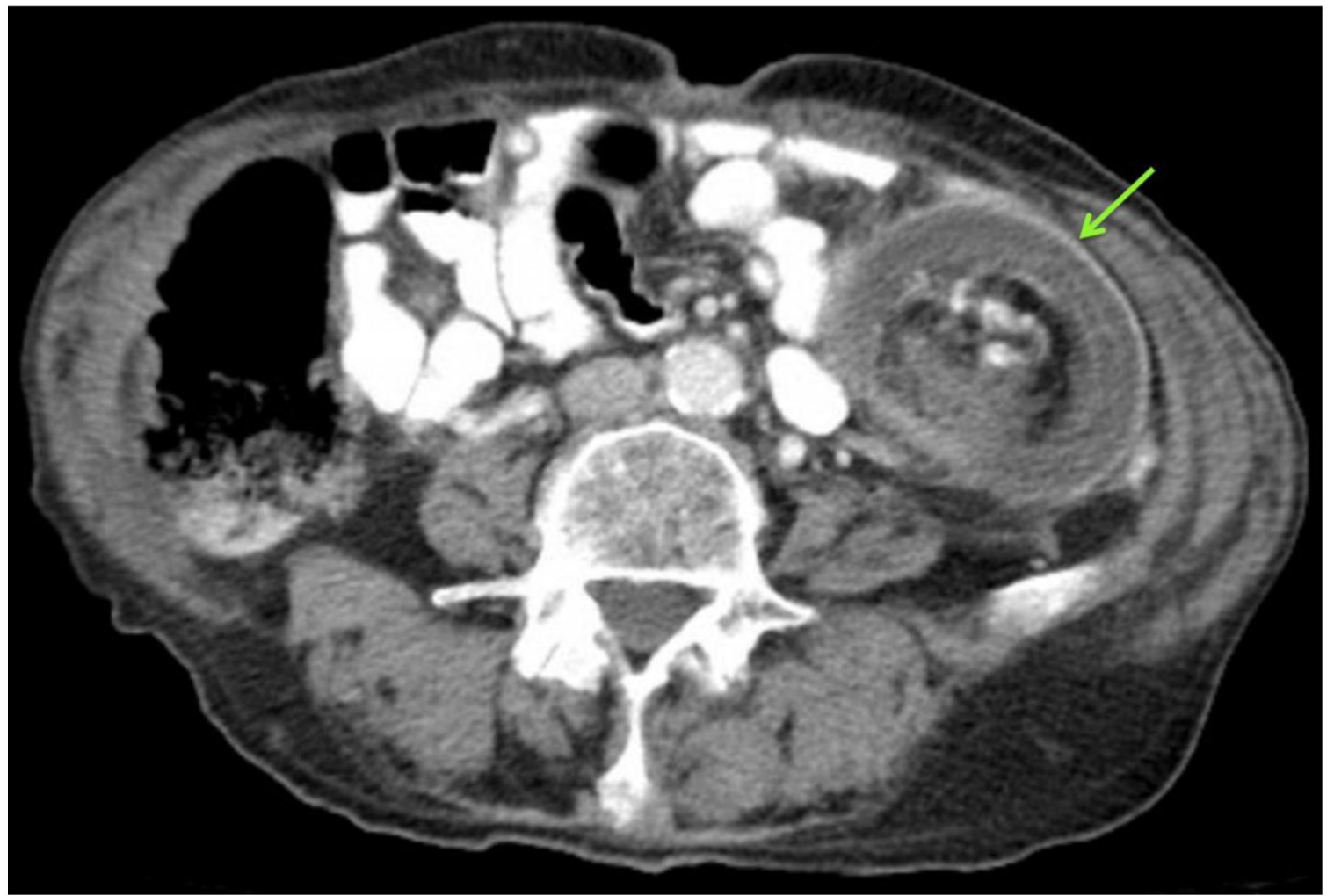

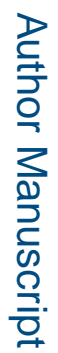

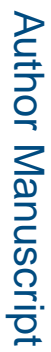




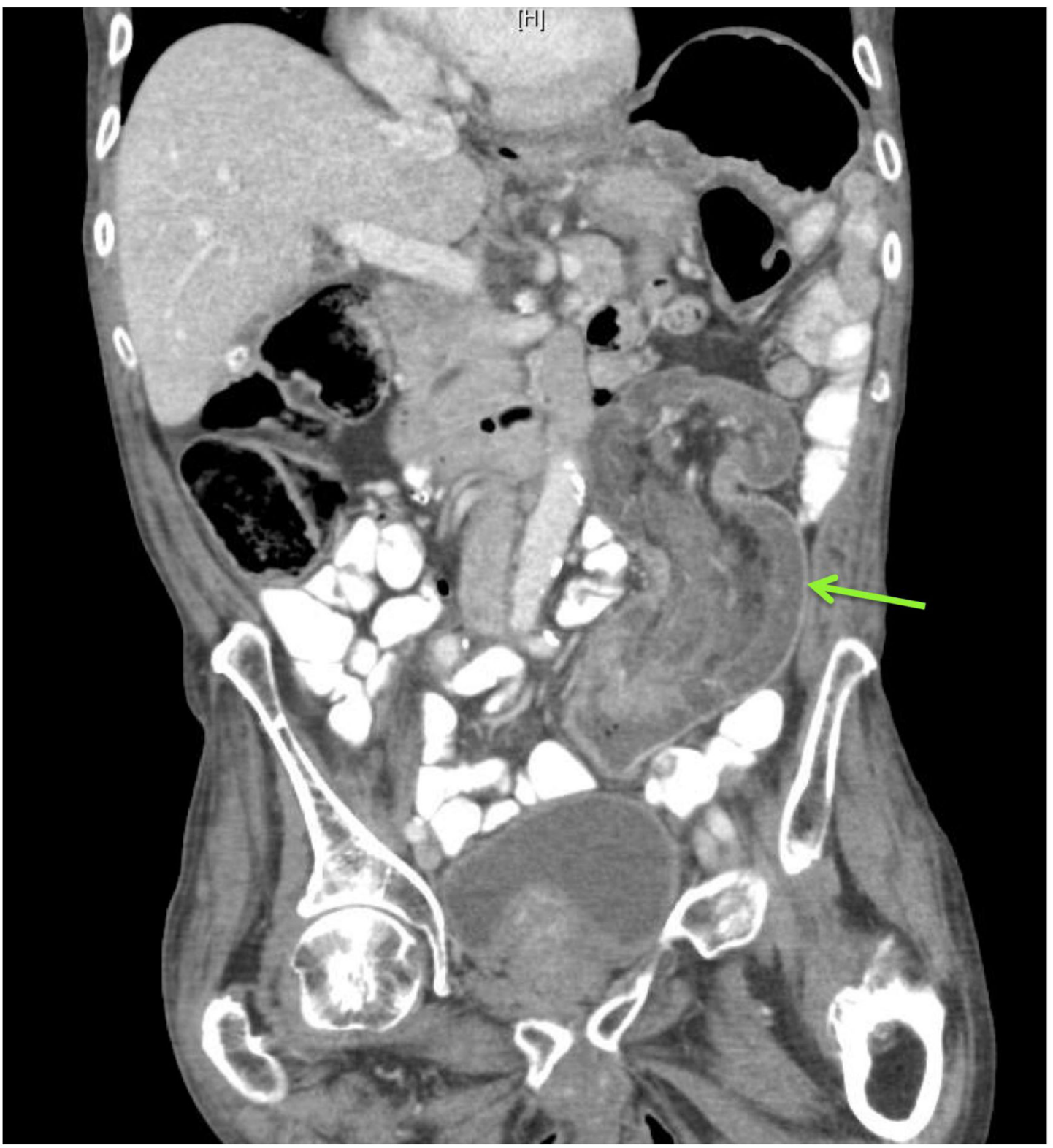

Figure 1 -.

Colocolic intussusception on CT scan is characterized by a "target-type" (a) or "sausageshaped" (b) lesion with a layered appearance, which is caused by mesentery and mesenteric vessels within the lumen. 


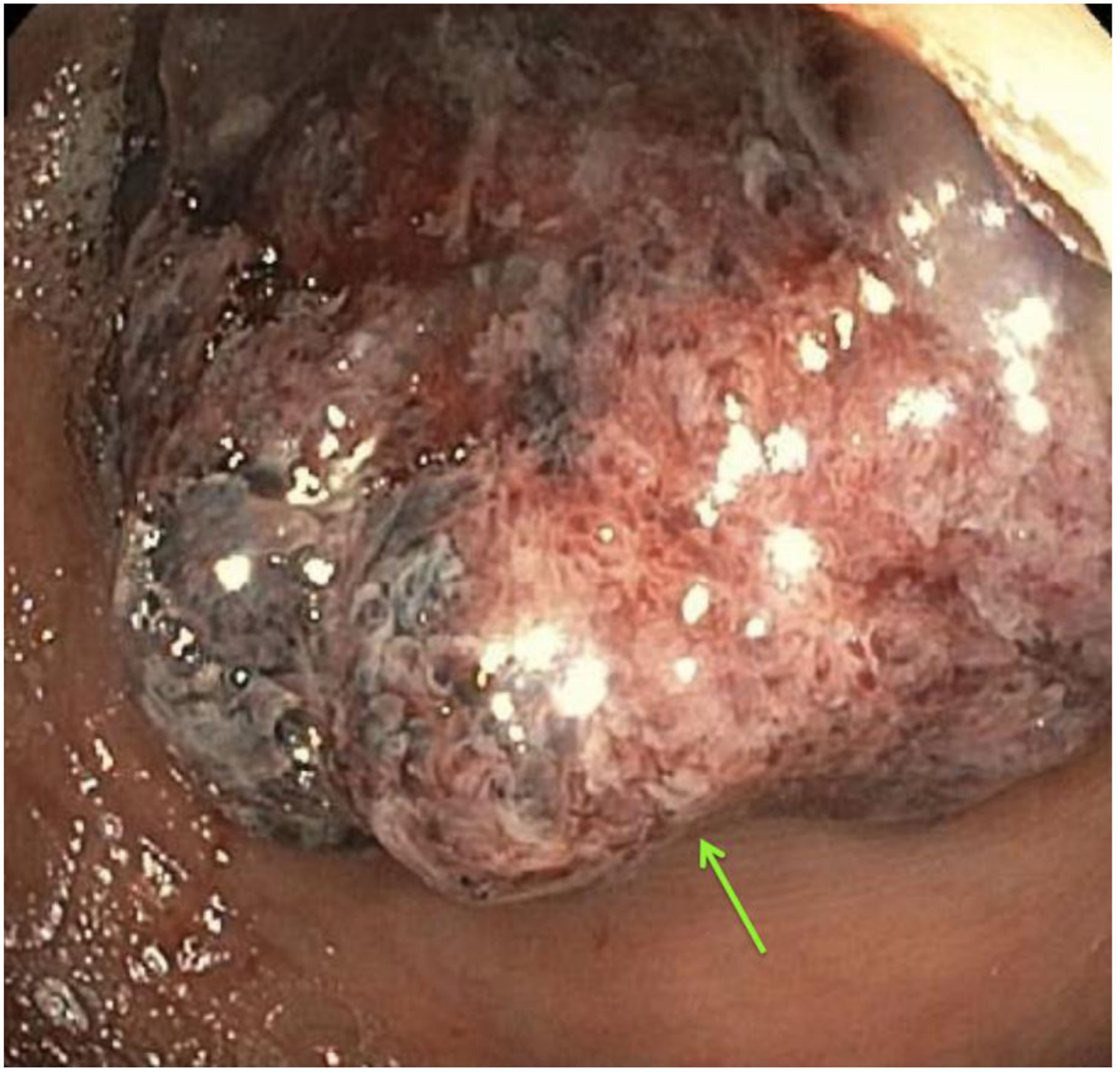

Figure 2 -.

Direct visualization of the intussusceptum on flexible sigmoidoscopy. 